\title{
Internal and External Factors Impacting Inside Sales Employee Turnover
}

\author{
By \\ Dennis H. Kimerer, University of South Florida
}

\begin{abstract}
Why Employee Turnover?
Employee turnover is a concern of any business and how to best manage and curtail the loss of good employees. Some turnover is good, but how do you define what is good turnover versus bad turnover, and what factors impact this critical business metric? Are there positions within an organization more business impacting
\end{abstract} than others? The research conducted looked at both internal and external factors impacting inside sales executives to leave their current employer for one who may be around the corner or down the street. Central Florida including the greater Orlando area has numerous inside sales organizations employing hundreds of inside sales executives. Some notable names include ADP, Spectrum, Staples, CenturyLink, Sprint, Liberty Mutual, Finestra, and many smaller companies.

\section{What is Inside Sales?}

The typical Inside Sales office is a large single or multi-floor office building lined with cubicles for the employees to work and call home for the next eight to ten hours, depending on their shift. The cubicles will have a desk, computer, and phone; standalone or phone software in the computer. The computers will utilize the typical suite of office products from one supplier or another, one form of customer relationship management software (CRM) and have access to proprietary tools and software programs unique to the business. More progressive offices have opted for a more open atmosphere with many conveniences available to help mitigate the monotony of inside sales

\section{Why Inside Sales?}

Inside sales offices have gained recognition as a viable partner, and sometimes competitor with direct sales simply because they can provide the same service levels as direct sales at a reduced cost as well as generate new business across a much larger footprint. This is accomplished through internal efficiencies desired by businesses today. Customers have grown accustomed to the availability of an inside salesperson, who is usually only a phone call or email away, however the Achilles heel for inside sales could be the impact employee turnover has on business continuity.

The focus of my research project was to answer two questions many companies would like to know and, by doing so, mitigate the causes of high employee turnover. The two questions are:

1. What are the internal factors of an organization that impact inside sales performers to leave their current employer?

2. What are the external factors of an organization that impact inside sales performers to leave their current employer?

Keywords: Turnover, Dynamic, Flexibility, Management, Compensation, Environment, External, Inter nal, Support

Copyright $\odot$ 2020, Dennis H. Kimerer. This article is published under a Creative Commons BY-NC license. Permission is granted to copy and distribute this article for non-commercial purposes, in both printed and electronic formats 
The amount of research articles and reports involving employee turnover number are numerous. Books have been written, just about every industry journal has published articles, academics have discussed the issue, high levels of employee turnover persist. Employee turnover in the sales profession fluctuates at an astonishing level, leaving management baffled. Research provides a large amount of information that identifies one of the major problems, which is communication between salesperson and management, but there are many others as my research has uncovered.

\section{The Study}

A total of 15 qualitative interviews were conducted over a 60-day period. The interviews included 10 male and five female participants, all of whom met the requirements to take part in the survey. All participants had a minimum of six years sales experience and had left more than one sales position; some had worked at three. The total number of years in sales ranged from six years to more than 20 . The results from the interviews provided data for 32 positions that had been left. The study design focused on inside sales organizations in a city in the United
States. Inside sales representatives were recruited through different forms, including word of mouth, direct recruitment, and social media. If participants did not meet the following requirements, they were disqualified:

- Have worked at or currently work as an inside salesperson

- Need the personal experience to draw on

- Office is in Central Florida (Metropolitan Orlando)

- Are at least 22 years old to avoid lack of maturity

- Have worked in inside sales for a minimum of 2 years

Completed transcripts of all interviews were uploaded to Nvivo 12 for analysis and coding. The files were uploaded as a case and as an interview. Uploading each as a case allowed me to categorize each by four areas: male or female, number of years in sales, number of sales positions held, and number of inside sales opportunities available to them. The justification for these groupings allowed me to compare answers and analyze responses based on these groups. The gender grouping provided comparisons between male and female interviewees. Number of years in sales

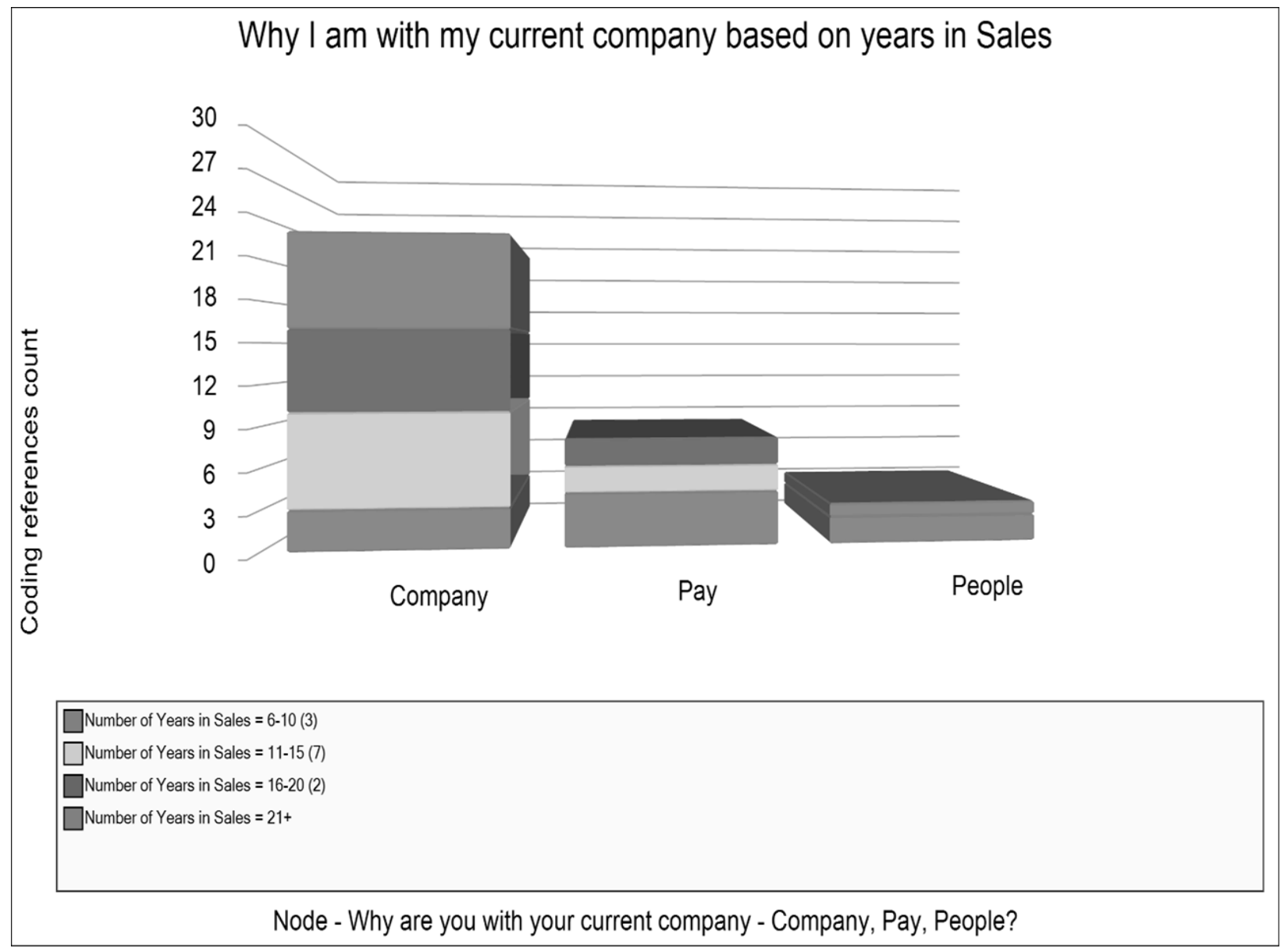

Figure 1: Main reason individuals are with current company (by years w/ company) 
provided a comparison between non-tenured and tenured interviewees (see Figure 1). Number of sales positions held offered a glimpse into how mobile the interviewees were based on the number of sales positions held to date. Number of inside sales opportunities available provided the interviewees' views on the number of alternatives they had.

The purpose of the question, "why are you with your current company" was to validate whether what I had been told throughout the interview was in line with their new company. In other words, did participants feel that by leaving their previous employer, they improved at least one aspect that was important to them? Many of the results focused on issues with past management as well as company policies. Much was presented about compensation and how inside salespeople follow a compensation plan. Interestingly, the word cloud shows compensation is quite low on the list of words and does not make the top 10 list of most frequent words. "Flexibility" is in the top space followed by the word "good" (see Figure 2)

Internal factors far outweighed the external factors. Data collected focused on the work environment, specifically the facility, the tools made available to the salespeople to do the tasks required, and the operational support such as marketing, training, and operations. From there, the discussion focused on the goals of the company and participants' individual goals. The next area discussed was what participants liked most about the company they had left followed by what they liked least. This questioning led into a discussion regarding the management they worked with and the main reason for them to leave. This questioning was repeated for each company the par-

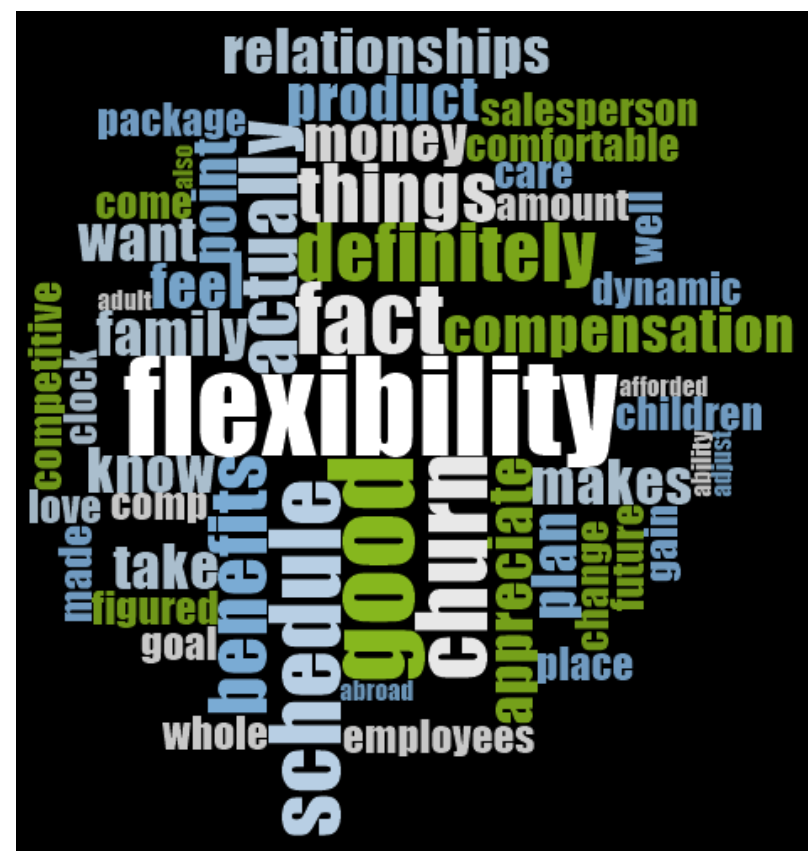

Figure 2: Word cloud of key words from interviews ticipants had worked with in an inside sales capacity. Positions that were not sales were disqualified and the questions were stopped for those positions. The final area of the interview targeted internal factors as an opportunity for participants to share any final comments or add areas they felt the discussion had missed.

The research was impacted by a few different limitations and these will help define future research. Most significant was the number of interviews conducted. I would have liked to have 10 additional interviews for a total of 25 . In addition, the mix between male and female was weighted more towards men and I would have liked to have seen more of a balance. Unfortunately, when asking for volunteers you may not have the ability to balance the demographics. Another area that was not discussed in the research was information about each participants performance. Sales requires a level of sustained performance in order to avoid being terminated. Even though the participants who participated had left their previous position, the question remains if they were performing at a level that would ensure continued employment with their previous company.

\section{Findings}

Following are key points from my research and additional details on each can be found in my complete dissertation defense by searching Muma ProQuest.

- Work environment, tools, operational support, and goals were mixed with minor impact

- $83 \%$ replies mention lack of future, hiring practices, giant disconnect

- Supportive or non-supportive manager is a major attribute

- $56 \%$ of jobs left were controllable-toxic culture, no advancement, not rewarding

- $72 \%$ are with their current employer for nonpay related reasons

- Schedule flexibility

- Work/life balance

- Advancement

- $100 \%$ of participants have been recruited multiple times

- $100 \%$ of participants knew of multiple sales offices within driving distance in Central Florida

\section{Conclusions}

Internal factors far outweighed external factors in my research as a main contributor to employee turnover. In addition, compensation was not the main reason contributing to employee turnover and in fact did not make the top 10 list of words coded in my research. The results showed the importance of dynamics and flexibility in the work environment as well as the performance indicators. The following provide a summary of the sentiment from participants. 
- Companies focus on customer churn, only minimally on employee churn

- Salespeople have mobility and are not afraid to move

- Inside sales in general is treated like the red-headed stepchild

- Internal factors outnumbered external

- Dynamic goals and flexibility of work/life balance are important

- Non-pay related issues accounted for more turnover than pay related

\section{Future}

My research concluded the need for additional research, especially in the area of flexibility of the company and the impact of dynamic goals from compensation to key performance indicators. In the inside sales arena key performance indicators focus on calls made, talk time, appointments set, opportunities identified, and finally opportunities closed. Overall, participants felt previous employers were too rigid and incapable of modifying requirements

- Expand the topic and more research
- Application of dynamic schedules, KPI's, scripting, quotas...etc.

- Flexibility

\section{Where to Find Out More}

Additional information can be found by accessing the dissertation defense article "Controlling Turnover in an Inside Sales Organization: What are the Contributing Factors" by Dennis Kimerer. This article will be published in the University of South Florida Scholarly journals and will be searchable via ProQuest ID 27543842. Additional question may be directed to the author Dr. Dennis Kimerer at dkimerer@mail.usf.edu or by telephone at 813-858-3053.

Review
This article was accepted under the constructive
peer review option. For futher details, see the de-
scriptions at:
http://mumabusinessreview.org/peer-review-op-
tions/

\section{Author}

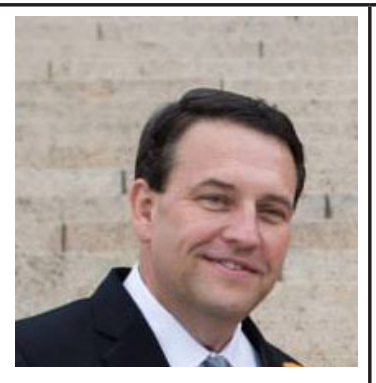

Dennis H. Kimerer is an accomplished sales leader with a focus on providing business customers the latest in technology across many platforms. He currently manages a sales and retention team of nine at CenturyLink's enterprise inside sales organization, located in Apopka, Fl. He graduated from Stetson University with a Bachelor of Science in Business Administration (B.S.) in May of 2011. He graduated with a Master of Business Administration (M.B.A.) in August of 2013 from the University of Tampa (UT) and a Master of Science in Marketing (M.S.) in May 2016 from UT. In December 2019 he graduated with a Doctor of Business Administration from the University of South Florida's Muma College of Business. 